\title{
Microsurgical resectability, outcomes, and tumor control in meningiomas occupying the cavernous sinus
}

\author{
Anil Nanda, MD, MPH, ${ }^{1}$ Jai Deep Thakur, MD, ${ }^{1}$ Ashish Sonig, MS, MCh, MD, ${ }^{2}$ and \\ Symeon Missios, MD'
}

1Department of Neurosurgery, Louisiana State University Health Science Center, Shreveport, Louisiana; and 2Department of
Neurosurgery, Gates Vascular Institute, Buffalo General Medical Center, Buffalo, New York

OBJECTIVE Cavernous sinus meningiomas (CSMs) represent a cohort of challenging skull base tumors. Proper management requires achieving a balance between optimal resection, restoration of cranial nerve $(\mathrm{CN})$ function, and maintaining or improving quality of life. The objective of this study was to assess the pre-, intra-, and postoperative factors related to clinical and neurological outcomes, morbidity, mortality, and tumor control in patients with CSM.

METHODS A retrospective review of a single surgeon's experience with microsurgical removal of CSM in 65 patients between January 1996 and August 2013 was done. Sekhar's classification, modified Kobayashi grading, and the Karnofsky Performance Scale were used to define tumor extension, tumor removal, and clinical outcomes, respectively.

RESULTS Preoperative CN dysfunction was evident in $64.6 \%$ of patients. CN II deficits were most common. The greatest improvement was seen for CN V deficits, whereas CN II and CN IV deficits showed the smallest degree of recovery. Complete resection was achieved in $41.5 \%$ of cases and was not significantly associated with functional CN recovery. Internal carotid artery encasement significantly limited the complete microscopic resection of CSM ( $p<0.0001)$. Overall, $18.5 \%$ of patients showed symptomatic recurrence after their initial surgery (mean follow-up 60.8 months [range 3-199 months]). The use of adjuvant stereotactic radiosurgery (SRS) after microsurgery independently decreased the recurrence rate $(p=0.009$; OR 0.036; 95\% $\mathrm{Cl} 0.003-0.430)$.

CONCLUSIONS Modified Kobayashi tumor resection (Grades I-IIIB) was possible in $41.5 \%$ of patients. CN recovery and tumor control were independent of extent of tumor removal. The combination of resection and adjuvant SRS can achieve excellent tumor control. Furthermore, the use of adjuvant SRS independently decreases the recurrence rates of CSM.

http://thejns.org/doi/abs/10.3171/2015.3.JNS142494

KEY WORDS cavernous sinus; meningiomas; Gamma Knife; microsurgery; oncology; stereotactic radiosurgery

We shall not cease from exploration, and the end of all our exploring will be to arrive where we started and know the place for the first time.

$$
- \text { T. S. Eliot }{ }^{14}
$$

Cavernous sinus meningiomas (CSMs) represent a subset of intracranial tumors that continue to pose a formidable challenge to neurosurgeons. The various factors contributing to the challenging management of CSMs include not only their location, which limits their resectability and increases the risk of injuring critical neurovascular structures, but also achieving long-term tumor control and maintaining or improving patient quality-of-life outcomes. ${ }^{1,5}$, $6,9,10,13,20,21,27,30,32,38,41,44$
Initially, CSMs were deemed inoperable due to the considerable mortality and morbidity related to removal of the tumor from what was deemed a surgically inaccessible area. With the introduction of the operating microscope and advances in neuroimaging, resection of these tumors became a realistic goal. The advances in microneurosurgical techniques in the 1980s and early 1990s allowed attempts at aggressive resection of these tumors. In the last 2 decades, the enthusiasm for aggressive resection has been tempered and the pendulum has swung toward a more conservative surgical strategy for treating the tumors of the parasellar compartment. Major factors that seem to be responsible for this paradigm shift include the efficacy and

ABBREVIATIONS CN = cranial nerve; $\mathrm{CND}=\mathrm{CN}$ dysfunction; $\mathrm{CS}=$ cavernous sinus; $\mathrm{CSM}=\mathrm{CS}$ meningioma; $\mathrm{ECA}=$ external carotid artery; $\mathrm{FT}=$ frontotemporal; $\mathrm{FTO}$ = FT craniotomy with orbital osteotomy; FTOZ = FT orbitozygomatic; ICA = internal carotid artery; KPS = Karnofsky Performance Scale; MF = middle fossa; RT = radiotherapy; SRS = stereotactic radiosurgery.

SUBMITTED October 31, 2014. ACCEPTED March 30, 2015

INCLUDE WHEN CITING Published online January 8, 2016; DOI: 10.3171/2015.3.JNS142494. 
safety of postoperative radiosurgery on subtotally resected meningiomas, histological evidence supporting cranial nerve $(\mathrm{CN})$ infiltration by meningiomas, and greater consideration of the impact of postoperative outcomes on the patients' quality of life. $15,24,30$

There is great variability in the literature with regard to the optimal treatment modality for CSM (Tables 1 and $2^{1,6,9,13,27,30,32,41}$. Outcomes after treatment with stereotactic radiosurgery (SRS) have been frequently reported. ${ }^{12,17,19,28,33,34,40,42-44,47}$ Recent studies highlight the efficacy of SRS in the treatment of meningiomas restricted to the parasellar space. ${ }^{44}$ However, for symptomatic meningiomas that are either confined within the CS or that are invading the CS from another primary site, resection and decompression remain a viable treatment modality. Meningiomas occupying the CS represent a heterogeneous group of tumors originating and extending over different anatomical skull base surfaces; thus, surgical management and outcomes may vary. The objective of this study was to describe our experience with the surgical management of CSM at our institution and develop an outline for the management of such a heterogeneous group of tumors, based on their anatomical location. We examined their resectability, recovery of $\mathrm{CN}$ function, influence of extent of resection, and factors predicting tumor recurrence after resection.

\section{Methods \\ Patient Population}

Approval was obtained from our institutional review board, which is accredited under the Human Research Protection Program. Then, a database prospectively maintained by the neurosurgery department, including medical charts and neuroimaging results, was retrospectively analyzed. Surgeries performed by a single surgeon were included in this study, in an attempt to limit bias. Between January 1996 and August 2013, a total of 65 patients underwent microsurgical removal of CSM as a primary treatment modality. The mean age at the time of surgery in our patient population was 55.4 years (range $21-85$ years) and the majority of patients were women (77\%). The mean follow-up time in our study was 60.8 months (range 3-199 months).

\section{Inclusion Criteria}

Patients with meningiomas that arose either within the CS (11 patients [17\%]; CSM either confined to the lateral wall or extended beyond the wall) or that demonstrated secondary involvement of the CS (54 patients [83\%]) and who underwent microsurgery as a primary treatment were included in our study (Table 3). Patients with CSM who underwent primary treatment with SRS were excluded.

\section{Tumor Grading and Classification}

Sixty-one (94\%) patients presented with WHO Grade I meningiomas and 4 patients with WHO Grade II meningiomas. There were no patients with WHO Grade III malignant meningiomas. Preoperative MRI was performed in all patients. Spatial anatomical location of the tumor was defined using Sekhar's classification to categorize the intracavernous extension ${ }^{36}$ (Table 4). The modified Kobayashi tumor removal grading system, given by DeMonte et al., was used to define the tumor removal ${ }^{10}$ (Table 5).

\section{Surgical Strategies}

Purely intracavernous, asymptomatic meningiomas or those with mild, nonimpairing symptoms such as occasional headaches have been primarily treated with SRS at our center over the past decade. Microsurgery is recommended as the primary treatment modality for patients with frequent activity-impairing symptoms or cranial neuropathies, or with tumors in proximity to the optic pathway and brainstem (Table 6). The typical surgical approach involves safe maximal resection of the extra- and intracavernous tumor components with a goal to decompress the optic apparatus, brainstem, or involved CNs transgressing the lateral wall of the CS. Surgical intervention also allows for histopathological diagnosis and grading, which dictates future management. The extent of resection is determined by the tumor characteristics and consistency; softer tumors typically allow for more extensive and safer decompression. The tumors occupying the medial aspect

\section{TABLE 1. Patterns of recurrence among contemporary SRS series for the management of CSM}

\begin{tabular}{|c|c|c|c|c|c|c|c|}
\hline \multirow[b]{2}{*}{ Authors \& Year } & \multirow{2}{*}{$\begin{array}{l}\text { Treatment Modality } \\
\text { for SRS }\end{array}$} & \multirow{2}{*}{$\begin{array}{l}\text { Total No. } \\
\text { of Lesions }\end{array}$} & \multirow[b]{2}{*}{ Follow-Up, Mos } & \multirow{2}{*}{$\begin{array}{c}\text { Failure, No. of } \\
\text { Cases (\%) }\end{array}$} & \multicolumn{3}{|c|}{ No. of Tumor Recurrences } \\
\hline & & & & & $<5 \mathrm{Yrs}$ & $5-10$ Yrs & $>10 \mathrm{Yrs}$ \\
\hline Skeie et al., 2010 & Primary + adjuvant & 100 & 82 (mean) & $15(15)$ & 10 & 2 & 3 \\
\hline dos Santos et al., 2011* & Primary + adjuvant & 88 & 86.8 (mean) & 9 (10.2) & 4 & 5 & 0 \\
\hline Spiegelmann et al., 2010* & Primary + adjuvant & 102 & 67 (mean) & $2(1.96)$ & 1 & 1 & 0 \\
\hline Kimball et al., 2009* & Primary + adjuvant & 49 & 50 (median) & $1(2)$ & 0 & 1 & 0 \\
\hline Hasegawa et al., 2007 & Primary + adjuvant & 111 & 62 (median) & $13(11.7)$ & 10 & 2 & 1 \\
\hline Pollock \& Stafford, 2005 & Primary & 49 & 58 (mean) & $0(0)$ & 0 & 0 & 0 \\
\hline Metellus et al., 2005 & Primary + adjuvant & 36 & 63.6 (median) & $2(5.55)$ & 2 & 0 & 0 \\
\hline Lee et al., 2002 & Primary + adjuvant & 159 & 39 (mean) & $9(5.6)$ & 7 & 2 & 0 \\
\hline Shin et al., 2001 & Primary + adjuvant & 40 & 42 (median) & $6(15)$ & 6 & 0 & 0 \\
\hline Roche et al., 2000 & Primary + adjuvant & 80 & 30.5 (median) & $4(5)$ & 4 & 0 & 0 \\
\hline Totals & & 814 & 58 (average of means/medians) & $61(7.5)$ & $44(72 \%)$ & $13(21 \%)$ & $4(7 \%)$ \\
\hline
\end{tabular}

* Linear accelerator-based radiosurgery. 
TABLE 2. Patterns of recurrence among contemporary primary microsurgical series for the management of CSM*

\begin{tabular}{|c|c|c|c|c|c|c|c|c|}
\hline \multirow[b]{2}{*}{ Authors \& Year } & \multirow[b]{2}{*}{ Location } & \multirow[b]{2}{*}{ Treatment Modality } & \multirow{2}{*}{$\begin{array}{l}\text { Total No. of } \\
\text { Lesions }\end{array}$} & \multirow{2}{*}{$\begin{array}{c}\text { No. of } \\
\text { Recurrences (\%) }\end{array}$} & \multirow{2}{*}{$\begin{array}{c}\text { Mean } \\
\text { Follow-Up }\end{array}$} & \multicolumn{3}{|c|}{ Time of Recurrence } \\
\hline & & & & & & $<5 \mathrm{Yrs}$ & $5-10$ Yrs & $>10 \mathrm{Yrs}$ \\
\hline Present study† & Primary + secondary & Surgery w/ or w/o SRS/RT & 65 & $12(18.4)$ & $60.8 \mathrm{mos}$ & 8 & 4 & 0 \\
\hline Pichierri et al., 2009 & Primary + secondary & Surgery w/ or w/o SRS/RT & 147 & $36(24.5)$ & $9.7 \mathrm{yrs}$ & NA & NA & NA \\
\hline Sindou et al., 2007 & Primary + secondary & Surgery & 100 & $11(13.25)$ & $8.3 \mathrm{yrs}$ & NA & NA & 0 \\
\hline Abdel-Aziz et al., 2004 & Sphenocavernous & Surgery & 38 & $4(10.5)$ & 96 mos & 1 & 3 & 0 \\
\hline Maruyama et al., 2004 & Primary + secondary & Surgery w/ or w/o SRS/RT & 23 & $2(8.7)$ & $47 \mathrm{mos}$ & 2 & 0 & 0 \\
\hline Dufour et al., 2001 & Primary & Surgery w/ or w/o SRS/RT & 17 & $2(11.7)$ & $6.1 \mathrm{yrs}$ & 2 & 0 & 0 \\
\hline O'Sullivan et al., 1997 & Primary + secondary & Surgery & 39 & $4(10.25)$ & 24 mos & 4 & 0 & 0 \\
\hline De Jesús et al., 1996 & Primary + secondary & Surgery & 119 & $14(11.76)$ & $33.8 \mathrm{mos}$ & 10 & 4 & 0 \\
\hline Cusimano et al., 1995 & Primary + secondary & Surgery & 89 & $6(6.74)$ & $28 \mathrm{mos}$ & 6 & 0 & 0 \\
\hline DeMonte et al., 1994 & Primary + secondary & Surgery & 41 & $5(12.2)$ & 45 mos & 4 & 1 & 0 \\
\hline Totals & & & 678 & $96(14.2)$ & $62.4 \mathrm{mos}$ & 37 & 12 & 0 \\
\hline
\end{tabular}

$\mathrm{NA}=$ not available; $\mathrm{RT}=$ radiotherapy.

* Recurrence is calculated according to individual study protocol (e.g., Sindou et al. calculated recurrence among the surviving patient population).

$\dagger$ One patient had a recurrence 60 months after surgery, which was treated by Gamma Knife surgery. One hundred twenty-three months after Gamma Knife surgery, the patient again had recurrence and was treated by microsurgery. This patient's recurrence 123 months after Gamma Knife surgery is not included in the column ">10 yrs" because the data collected address recurrence after microsurgery.

of the CS are typically unresectable. Radical resection of CSM followed by external carotid artery-internal carotid artery (ECA-ICA) bypass is not the typical management protocol for histologically benign meningiomas, both in our practice and in the literature. ${ }^{1,5,32,44}$ In cases where it was critical to assess the relationship between the tumor and the cavernous ICA, preoperative MR angiography or 4-vessel cerebral angiography was performed.

If there was significant (generally defined by modified Kobayashi tumor removal Grade IVB or V) residual tumor after resection, adjuvant SRS was recommended. Typical radiographic follow-up includes an MRI every 6 months for the first 2 years, annually for the next 3 years, and every other year thereafter. SRS is recommended for patients with asymptomatic tumor progression; patients who continue to progress despite radiation are offered microsurgery.

\section{Surgical Approaches}

Thirty-nine $(60 \%)$ of 65 craniotomies were performed using a frontotemporal orbitozygomatic (FTOZ) approach, $4(6.2 \%)$ were performed via a frontotemporal craniotomy with orbital osteotomy (FTO), a frontotemporal (FT) approach was performed for $10(15.4 \%)$ craniotomies, and

TABLE 3. Origin of CSM in the present study

\begin{tabular}{lc}
\hline \multicolumn{1}{c}{ Origin } & No. of Patients (\%) \\
\hline Primary CS & $11(17)$ \\
\hline Sphenoid wing & $27(41)$ \\
\hline Petroclival & $9(14)$ \\
\hline Sphenopetroclival & $6(9)$ \\
\hline Sphenopetrosal & $3(5)$ \\
\hline Sphenoclinoidal & $2(3)$ \\
\hline Clinoidal & $1(2)$ \\
\hline Tuberculum sellae & $6(9)$ \\
\hline
\end{tabular}

an extended middle fossa (MF) transpetrous approach was used in $12(18.5 \%)$ of the cases. The advantages of adding an orbitozygomatic or orbital osteotomy alone to the traditional FT craniotomy have been previously elucidated by various cadaveric studies and 3D quantitative models. ${ }^{3,7,26,35,45,50}$ FTOZ has been shown to increase the surgical freedom and the projection angle while decreasing the amount of brain retraction required for adequate exposure. ${ }^{3}$ However, in recent years, our experience in treating small to midsized sphenocavernous meningiomas and sphenoclinoidocavernous meningiomas has suggested that adequate exposure and maximal resection was possible with an FT craniotomy alone, followed by a combined extradural-intradural approach (Figs. 1 and 2 upper), as thoroughly described previously. ${ }^{1,5,11,16,18,41}$ An obvious advantage from exposure with an FTOZ craniotomy was noted for the central skull base tumors that had a more superior extension and/or occupied the floor of the MF. Furthermore, for some skull base meningiomas, a cranial base approach allowed identification and interruption of the anastomotic connection of ECA-ICA from which they derive their blood supply, as explained by Yamaki et al. ${ }^{49}$ and Day. ${ }^{8} \mathrm{~A}$ brief overview of our surgical technique (depending upon the apparent origin and extension of the tumor) is given below.

TABLE 4. Tumors stratified according to Sekhar's classification to define spatial extension

\begin{tabular}{lc}
\hline \multicolumn{1}{c}{ Sekhar's Classification } & $\%$ of Patients \\
\hline $\begin{array}{l}\text { Grade I-tumors involve 1 region of the sinus \& do not } \\
\text { involve the ICA }\end{array}$ & 33.8 \\
\hline $\begin{array}{l}\text { Grade II -tumors occupy multiple regions of the sinus } \\
\text { \& displace but do not encase the ICA }\end{array}$ & 15.4 \\
\hline Grade III-tumors encase the ICA w/o narrowing & 26.2 \\
\hline Grade IV-tumors encase \& narrow the ICA & 18.5 \\
\hline Grade V-tumors involve both CSs \& encase the ICA & 6.2 \\
\hline
\end{tabular}


TABLE 5. Extent of resection according to the modified Kobayashi tumor removal grading system*

\begin{tabular}{|c|c|}
\hline Modified System of Kobayashi et al. & $\begin{array}{c}\text { No. of } \\
\text { Patients (\%) }\end{array}$ \\
\hline $\begin{array}{l}\text { Grade I-complete microscopic removal of tumor \& } \\
\text { dural attachment w/ any abnormal bone }\end{array}$ & $0(0)$ \\
\hline $\begin{array}{l}\text { Grade II-complete microscopic removal of tumor w/ } \\
\text { diathermy coagulation of its dural attachment }\end{array}$ & $23(35.4)$ \\
\hline $\begin{array}{l}\text { Grade IIIA-complete microscopic removal of intra- \& } \\
\text { extradural tumor w/o resection or coagulation of its } \\
\text { dural attachment }\end{array}$ & $1(1.5)$ \\
\hline $\begin{array}{l}\text { Grade IIIB_complete microscopic removal of intradural } \\
\text { tumor w/o resection or coagulation of its dural attach- } \\
\text { ment or any of its extradural extensions }\end{array}$ & $3(4.6)$ \\
\hline $\begin{array}{l}\text { Grade IVA_intentional subtotal removal to preserve } \\
\text { CNs or blood vessels w/ complete microscopic } \\
\text { removal of attachment }\end{array}$ & $14(21.5)$ \\
\hline Grade IVB - partial removal leaving tumor $\leq 10 \%$ in vol & $4(6.2)$ \\
\hline $\begin{array}{l}\text { Grade } V \text { - partial removal leaving tumor }>10 \% \text { in vol, or } \\
\text { decompression w/ or w/o biopsy }\end{array}$ & $20(30.8)$ \\
\hline \multicolumn{2}{|l|}{ * As described in De Monte et al. } \\
\hline \multicolumn{2}{|c|}{$\begin{array}{l}\text { Lesions that involve the lateral compartment of the CS, } \\
\text { that have breached it to involve the MF floor, or with sec- } \\
\text { ondary involvement of the CS are resected mainly via an } \\
\text { intradural approach. The dura over the frontal and tem- } \\
\text { poral lobes is opened and the tumor is debulked in an } \\
\text { anterolateral to posteromedial direction, thereby achiev- } \\
\text { ing appropriate neurovascular decompression. We have } \\
\text { noticed improved results in the recovery of CN III palsy }\end{array}$} \\
\hline
\end{tabular}

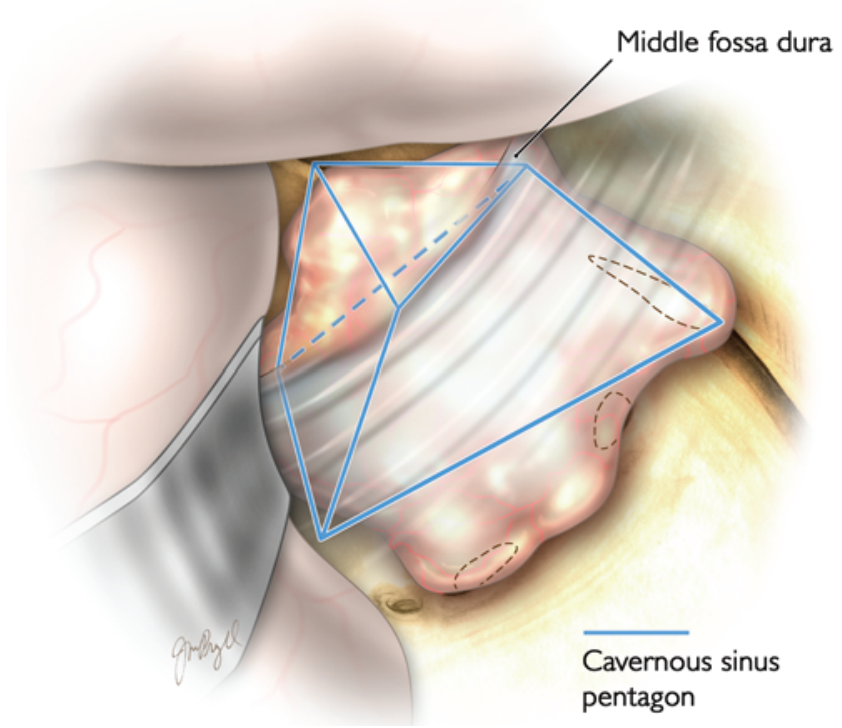

FIG. 1. View of the parasellar compartment after retracting the frontal and temporal lobes, similar to exposure of the CS in an extradural approach. The CS is shown in the form of a pentagon and a typical view of tumors occupying the parasellar compartment is further elucidated. The dura propria spans the lateral outer wall of the CS. To maximize the exposure, the sylvian fissure is opened and extra- and intradural approaches are combined. Copyright Anil Nanda. Published with permission. Figure is available in color online only.

if the nerve was decompressed from the posterior portion of the roof of the CS where CN III and CN IV enter (Fig. 2 upper). Careful dissection is required due to the risk of postoperative CN IV palsy. Wide exposure of the

TABLE 6. Summary of treatment strategies for CSM

\begin{tabular}{|c|c|c|c|c|}
\hline CSM Type & $\begin{array}{l}\text { Indication for Microsurgical Removal of CS } \\
\text { Component }\end{array}$ & Type of Approach* & $\begin{array}{l}\text { Intracavernous } \\
\text { ICA Encased }\end{array}$ & $\begin{array}{l}\text { Grades I-IIIB } \\
\text { Resection }\end{array}$ \\
\hline \multirow[t]{2}{*}{ Primary } & $\begin{array}{l}\text { Routine activity impaired by symptoms/neuropathy or } \\
\text { tumor in proximity to optic pathway/brainstem }\end{array}$ & $\begin{array}{l}\text { FT/FTOZ/extra- } \\
\quad \text { dural }\end{array}$ & Yes & No \\
\hline & & & No & No \\
\hline \multirow[t]{2}{*}{ Sphenoid } & As above & $\begin{array}{l}\text { FT/FTOZ/extra- } \\
\text { dural }\end{array}$ & Yes & No \\
\hline & & & No & Yes \\
\hline \multirow[t]{2}{*}{ Sphenoid $+\geq 1$ anatomical origin } & As above & & Yes & No \\
\hline & & & No & No \\
\hline Sphenoclinoidal & & FTOZ/extradural & & \\
\hline Sphenopetrosal & & FT/FTOZ & & \\
\hline Sphenopetroclival & & MF-TP & & \\
\hline \multirow[t]{2}{*}{ Tuberculum sellae } & As above & FTOZ & Yes & No \\
\hline & & & No & Yes \\
\hline \multirow[t]{2}{*}{ Cavernous-petroclival (CS $\geq$ petroclival) } & As above & $\begin{array}{l}\text { MF-TP w/ or w/o } \\
\text { FT/FTOZ }\end{array}$ & Yes & No \\
\hline & & & No & No \\
\hline \multirow[t]{2}{*}{ Petroclival-cavernous (petroclival > CS) } & As above & FTOZ† & Yes & No \\
\hline & & & No & Yes \\
\hline
\end{tabular}

$\mathrm{TP}=$ transpetrous.

* The extradural approach is usually reserved for cases where the tumor is in proximity to the optic canal or superior orbital fissure.

$\dagger$ If required, the FTOZ approach follows sequentially as a separate procedure after the retrosigmoid decompression of the major petroclival component. 

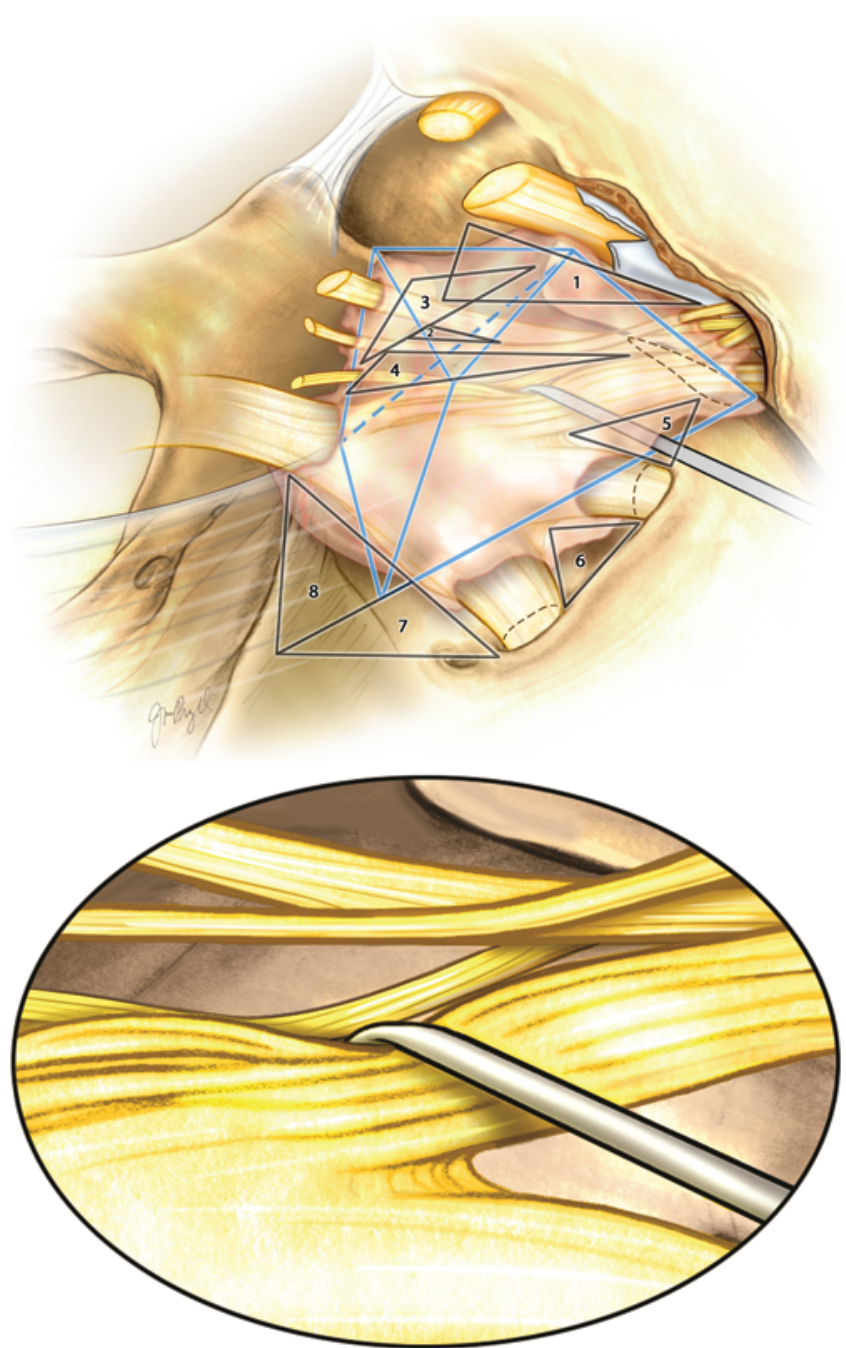

the anterior clinoid process improves the exposure of the clinoidal triangle of the CS. It is indicated for maximal resection of sphenocavernous and anterior clinoidal meningiomas that invade the CS and have anterior extension into the orbit or other MF foramina (Fig. 2 upper). An extradural approach that involves separating the subfrontal and subtemporal dura from the orbital roof and sphenoid wing, respectively, and exposing the anterior clinoid process, optic canal, superior orbital fissure, foramen rotundum, and foramen ovale is mainly indicated in lesions involving the optic canal or the MF foramina (Figs. 1 and 2 upper). In cases where the tumor is extending into the infratemporal fossa, respective foramina through which tumor is invading the skull base are drilled and unroofed to reach the infratemporal extension. The middle meningeal artery is identified at the foramen spinosum and coagulated to enhance the exposure (Fig. 3). The dura propria of the anteromedial temporal lobe is then elevated from the lateral wall of the CS and the latter is then mobilized in a fashion similar to that described elsewhere. . $^{1,5,9,16,18,46}$

The spheno-CSM tend to have a dissection plane in proximity to the lateral wall, thereby allowing a safe dissection of the tumor from the neural structures. ${ }^{1,8}$ The dura over the lateral wall of the CS is generally incised at the point of maximal bulge or followed in the direction of tumor growth. Otherwise, Parkinson's triangle is entered and extradural tumor debulking of the lateral wall is performed, including the anteromedial and anterolateral middle fossa triangles. If the tumor is invading Meckel's cave, the dura over the trigeminal ganglion is incised and the tumor is followed posteriorly and resected. Adequate tumor removal results in identification of Dorello's canal. CN VI is identified, decompressed, and exposed through

FIG. 2. Upper: The CS (pentagon) is shown with respect to CNs, CS triangles, and bony anatomy with respect to a tumor occupying the parasellar compartment and its surrounding space. CS triangles are labeled as 1) clinoidal (anterior clinoid process has been drilled); 2) oculomotor (medial or Hakuba's triangle); 3) supratrochlear (paramedian); 4) Parkinson's (infratrochlear) triangle; 5) anteromedial (Mullan's) triangle; 6) anterolateral; 7) posterolateral (Glasscock's) triangle; and 8) posteromedial (Kawase's) triangle. The inferolateral triangle containing the dural opening into Meckel's cave and the inferomedial triangle containing the cranial dural opening into Dorello's canal are not labeled in this figure. Dotted lines in the MF floor represent superior orbital fissure anteriorly, foramen rotundum between triangles 5 and 6 , and foramen ovale between triangles 6 and 7. Lower: An inset shows the nerve hook retracting the $\mathrm{V} 1$ branch of the trigeminal nerve for exposure of the sixth $\mathrm{CN}$. This is important especially when the patient with CS tumor has a sixth $\mathrm{CN}$ palsy. Sixth $\mathrm{CN}$ decompression using this maneuver may lead to better $\mathrm{CN}$ recovery. Copyright Anil Nanda. Published with permission. Figure is available in color online only.

sylvian fissure aids in tumor dissection through the arachnoid planes over the distal ICA and the proximal anterior cerebral artery and middle cerebral artery. The tumor is peeled away from the optic apparatus and pituitary stalk. Subsequently, the potential tumor-invaded spaces including the opticocarotid triangle and oculomotor carotid triangles are debulked, if required.

Extradural unroofing of the optic canal and removal of

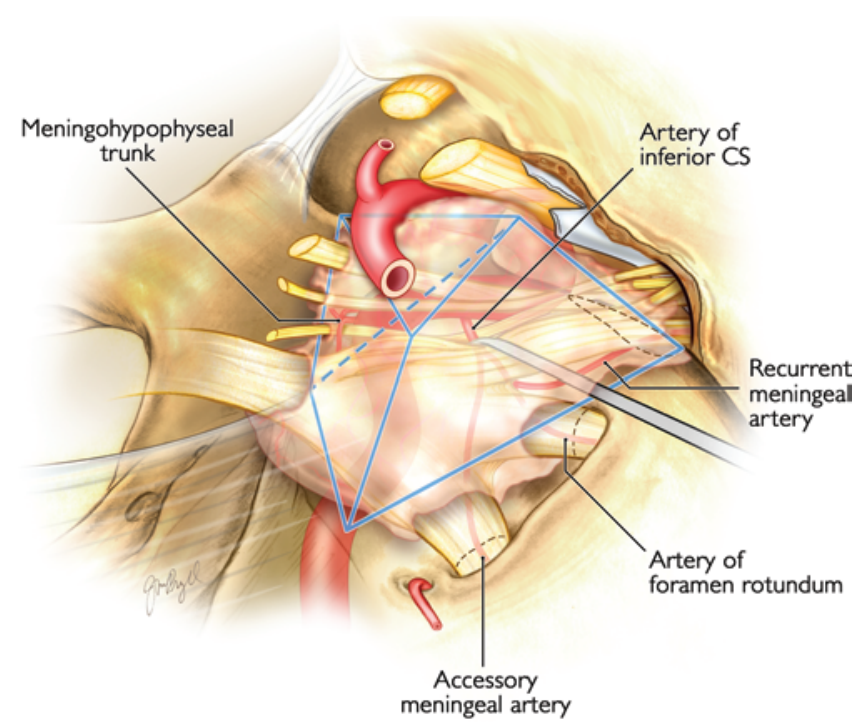

FIG. 3. The blood supply from the cavernous ICA, which may be encountered during tumor resection, is highlighted. The artery of the inferior CS usually branches off into the recurrent meningeal artery, artery of foramen rotundum, and accessory meningeal artery, exiting through the foramen ovale. These often supply the tumor capsule and are important tumor feeders that may have to be devascularized during skull base exposure. Another branch of the cavernous ICA shown is the meningohypophyseal trunk dividing into further branches. Copyright Anil Nanda. Published with permission. Figure is available in color online only. 
Parkinson's triangle (Fig. 2 lower). Tumor decompression at the site of Dorello's canal and/or through the infratrochlear triangle may facilitate improvement of associated $\mathrm{CN}$ VI palsy, if present (see Illustrative Case). Dissection of the tumor from the CNs is based on the ability to define an anatomical plane between them. Thick fibrous tumors, or calcified components within the CS that are adhered to CNs, are frequently left alone.

Petroclival meningiomas invading the CS were managed using different approaches. The MF, transzygomatic, and combined supra- and infratentorial transpetrosal approach provided optimal preclival decompression in our experience. Pregasserian combined with retrogasserian dissection, followed by maximal decompression of the CNs from the brainstem to their course through the lateral wall of the $\mathrm{CS}$, resulted in partial restoration of $\mathrm{CN}$ function for the majority of patients. Residual tumor in the posterior fossa may be subsequently removed through a retrosigmoid approach in a different setting.

Figures 1-5 elucidate, in a building block-like fashion, the complex relationship of the CS and its contents with the tumors occupying the parasellar compartment and surrounding areas.

\section{Outcome Variables and Statistical Methods}

1. Neurological deficits. The status of pre- and postoperative CND was assessed at the initial encounter and last follow-up available, respectively (Table 7). Non-CND complications were also noted. The association between the extent of resection and recovery of CNDs was analyzed using the Pearson chi-square test.

2 . Extent of resection. We examined the association between the extent of resection and Sekhar's classification using Fisher's exact test. The association between the ex-

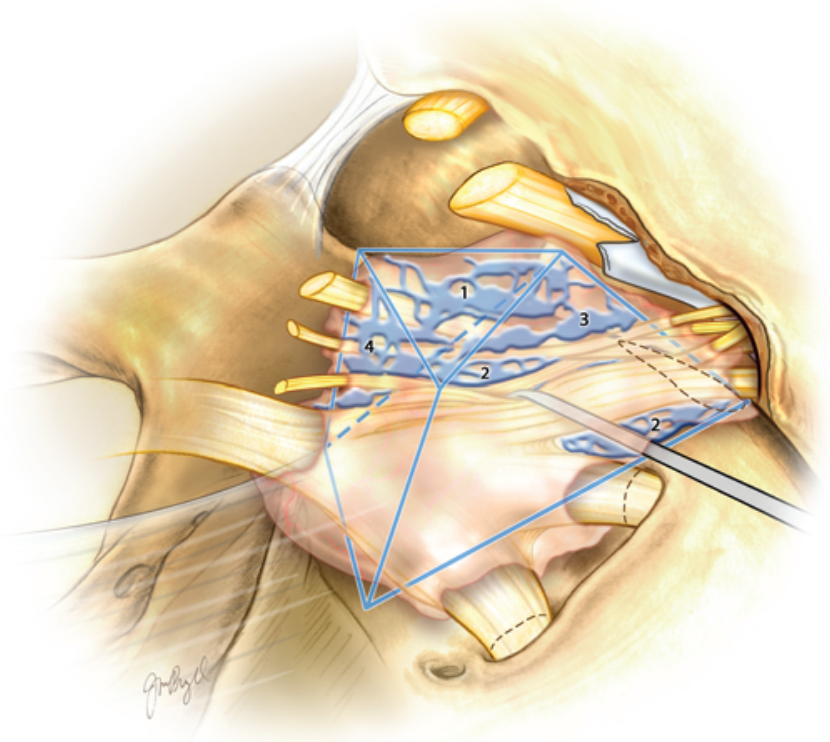

FIG. 4. The major venous spaces of CS that one has to be mindful of because sinus bleeding is commonly encountered during CS exploration are shown. 1) Superior group; 2) inferior group; 3) lateral group; and 4) posterior group. Copyright Anil Nanda. Published with permission. Figure is available in color online only.

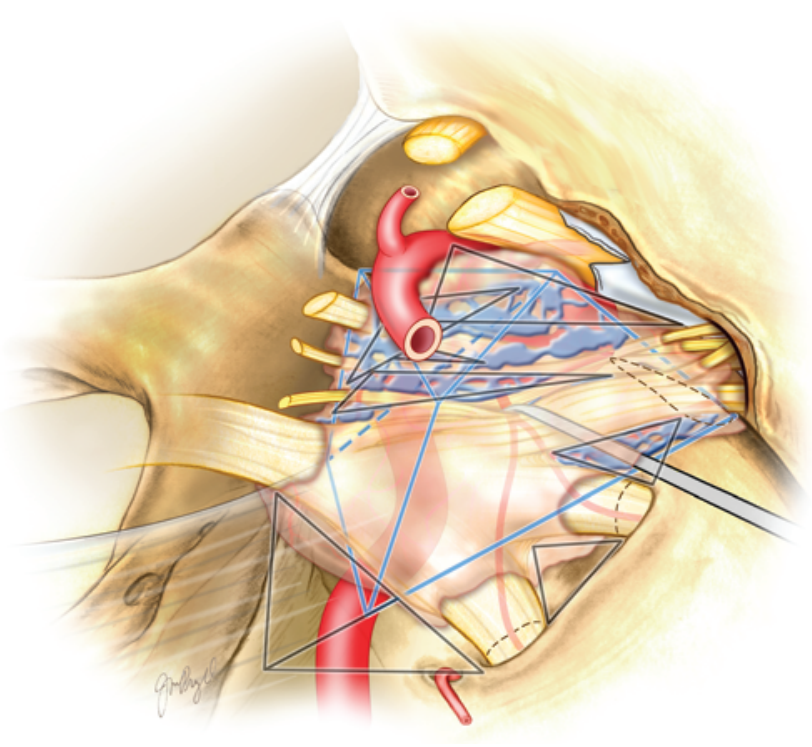

FIG. 5. The complex CS and its associated contents in relationship to the tumor occupying the parasellar compartment and surrounding spaces are shown. Copyright Anil Nanda. Published with permission.

tent of resection and tumor control was analyzed using the Pearson chi-square test.

3. Clinical outcome. The Karnofsky Performance Scale (KPS) was used to assess the clinical outcome in our patients. KPS scores were noted both preoperatively and at the last clinical follow-up. For purposes of our analysis, we defined good recovery as a similar or better KPS score at last follow-up compared with the preoperative KPS score. Patients who died of unrelated causes were excluded from the analysis $(n=3)$. The association of clinical outcomes with various pre- and postoperative variables was examined using the Pearson chi-square test or Fisher's exact test (Fisher's exact test was used if the number of samples in 1 of the $2 \times 2$ tables was $<5$ ) and Cox regression analysis.

4. Tumor control. We defined recurrence as worsening of existing symptoms or development of new symptoms correlating with radiological tumor growth. Any asymptomatic tumor growth was considered as a tumor progression. The patients were divided into 2 treatment subgroups, including 1) only microsurgery and 2) microsurgery plus adjuvant SRS to surgical residual. Cases where SRS was administered for tumor progression $(n=2)$ were not included in the analysis of recurrence. Complete resection was defined as $\geq$ Grade IIIA according to the modified Kobayashi tumor removal grading scale., ${ }^{1,30}$

All statistical analysis was done using SPSS software, version 20 (IBM).

\section{Results}

\section{Clinical Features}

Cranial Nerve Dysfunction

Preoperative CND was noted in $64.6 \%$ of patients. CN II dysfunction (43\% of patients) was most common, followed by CN III (24.6\%), CN V (12.3\%), CN VI (10.7\%), and CN IV (7.7\%). The status of CND at the last followup was assessed by using medical chart reviews and was 
TABLE 7. Breakdown of CND status at last follow-up*

\begin{tabular}{|c|c|c|c|c|c|c|c|c|}
\hline \multirow[b]{2}{*}{ Parameter } & \multicolumn{8}{|c|}{ No. of Patients (\%) } \\
\hline & $\mathrm{CN} \|$ & CN III & CN IV & CN V & CN VI & CN VII & Other & Proptosis \\
\hline Preop CND, long-term follow-up & 28 & 16 & 5 & 8 & 7 & 4 & 5 & 3 \\
\hline \multicolumn{9}{|l|}{ Recovery status } \\
\hline Worse & $3(11)$ & 0 & 0 & 0 & 0 & 0 & 0 & 0 \\
\hline No improvement & $10(35)$ & $3(19)$ & $2(40)$ & 0 & $2(28.5)$ & $1(25)$ & $2(40)$ & $1(33)$ \\
\hline Partial improvement & $12(43)$ & $9(56)$ & $2(40)$ & $4(50)$ & 0 & $3(75)$ & $3(60)$ & $2(67)$ \\
\hline Complete recovery & $3(11)$ & $4(25)$ & $1(20)$ & $4(50)$ & $5(71.5)$ & 0 & 0 & 0 \\
\hline Total preop CND & $(43)$ & $(24.6)$ & $(7.7)$ & (12.3) & $(10.7)$ & (6) & $(7.7)$ & $(4.6)$ \\
\hline New CND occurred postop, long-term follow-up & 0 & 16 & 6 & 3 & 4 & 2 & 4 & \\
\hline \multicolumn{9}{|l|}{ Recovery status } \\
\hline Worse & 0 & 0 & 0 & 0 & 0 & 0 & 0 & \\
\hline No improvement & 0 & $1(6.25)$ & $2(33)$ & 0 & $1(25)$ & $1(50)$ & $4(100)$ & \\
\hline Partial improvement & 0 & $5(31.25)$ & $3(50)$ & $1(33)$ & $2(50)$ & $1(50)$ & 0 & \\
\hline Complete recovery & 0 & $10(62.5)$ & $1(17)$ & $2(67)$ & $1(25)$ & 0 & 0 & \\
\hline Total new CNDs & $(0)$ & $(24.6)$ & (9.2) & $(4.6)$ & (6) & (3) & (6) & \\
\hline
\end{tabular}

* Because 1 patient can have multiple CNDs, the values are not cumulative for the total number of patients in the study.

based on the documented ophthalmological and neurological exams. $\mathrm{CN}$ functions were grouped into 4 categories: a) worse, b) no improvement, c) partial improvement, and d) complete recovery. A complete description of the recovery status of CND at the last follow-up is given in Table 7. Among the CNs coursing in the MF, CN V showed the most improvement on long-term follow-up (100\% of CNDs harboring $\mathrm{CN} \mathrm{V}$ deficits showed recovery [50\% complete, $50 \%$ partial]). CN VI showed the highest incidence of complete recovery (71.5\%). Of patients with $\mathrm{CN}$ II dysfunction, 54\% experienced recovery, either partial (43\%) or complete $(11 \%)$. Only $25 \%$ of patients with CN IV deficits experienced complete recovery. Overall, complete functional recovery of the CNs was found in 17 of the 73 (23.2\%) total postoperative $\mathrm{CN}$ deficits.

\section{Other Clinical Features}

The most common presenting symptom in our patient population was headache (69.2\%), typically located in the frontotemporal region. Patients occasionally presented with a history of migraine headaches that increased in intensity and frequency. Retro-orbital pressure, $\mathrm{CN}$ deficits, vision changes, seizures, nausea, and vomiting were frequent associated symptoms. Exophthalmos was noted in $4.6 \%$ of patients. Preoperative hemiparesis was evident in 5 cases.

\section{Resectability}

The extent of resection was defined by the modified Kobayashi tumor removal grading system ${ }^{10}$ based on postoperative imaging done within a month of the surgery (Table 5). Complete removal of the intradural and/or extradural tumor with or without resection or coagulation of its dural attachment (Kobayashi Grades I-IIIA) was achieved in $41.5 \%$ of cases (Figs. 6 and 7). Intentional subtotal resection to preserve neurovascular structures with complete removal of the dural attachment was performed in $21.5 \%$ of cases (Fig. 8). Partial removal of the tumor, leaving $\leq 10 \%$ in volume, was achieved in $6.2 \%$ of cases (Fig. 9), and > $10 \%$ of tumor was left behind in $30.8 \%$ of cases.

Based on Sekhar's classification, we assessed if the degree of ICA encasement (defined by $\geq$ Sekhar Grade III) influenced resectability. Complete microscopic resection was defined by Kobayashi Grades I-IIIA.1,30 For lesions with partial ICA encasement, complete resection was achieved in $12.1 \%$ of cases, whereas for lesions with no ICA encasement, complete resection was achieved in $71.8 \%$ ( $p<0.0001$, Fisher's exact test). The relationship between the modified Kobayashi tumor removal grades and the spatial anatomical location of the tumor (Sekhar's classification) is given in Table 8. Resectability based on the apparent origin of the tumor is shown in Table 9. Ag-

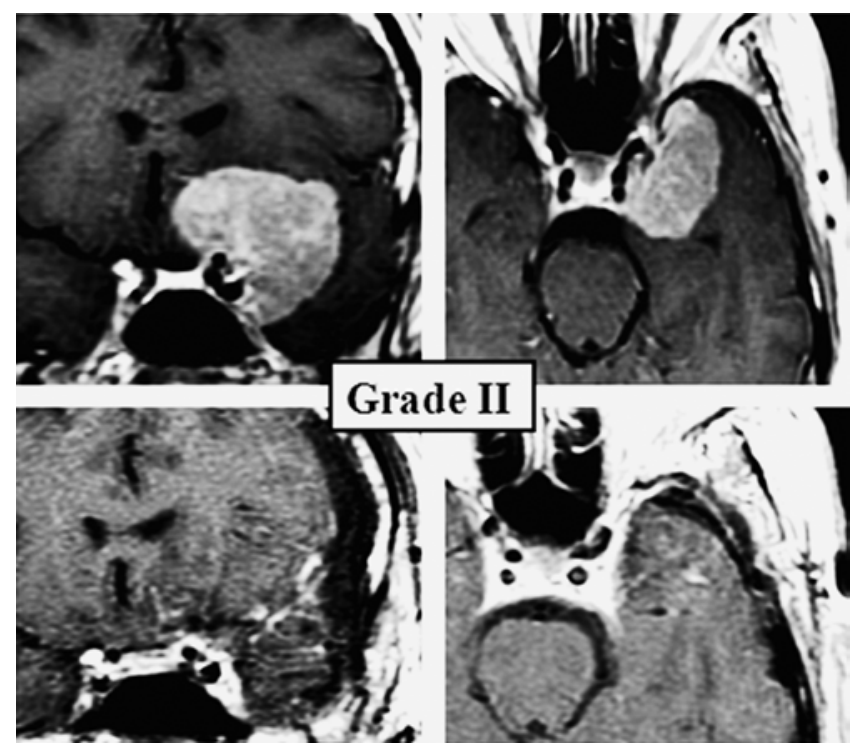

FIG. 6. Extent of resection is shown in T1-weighted MRI sequences obtained with contrast depicting modified Kobayashi Grade II tumor removal. 


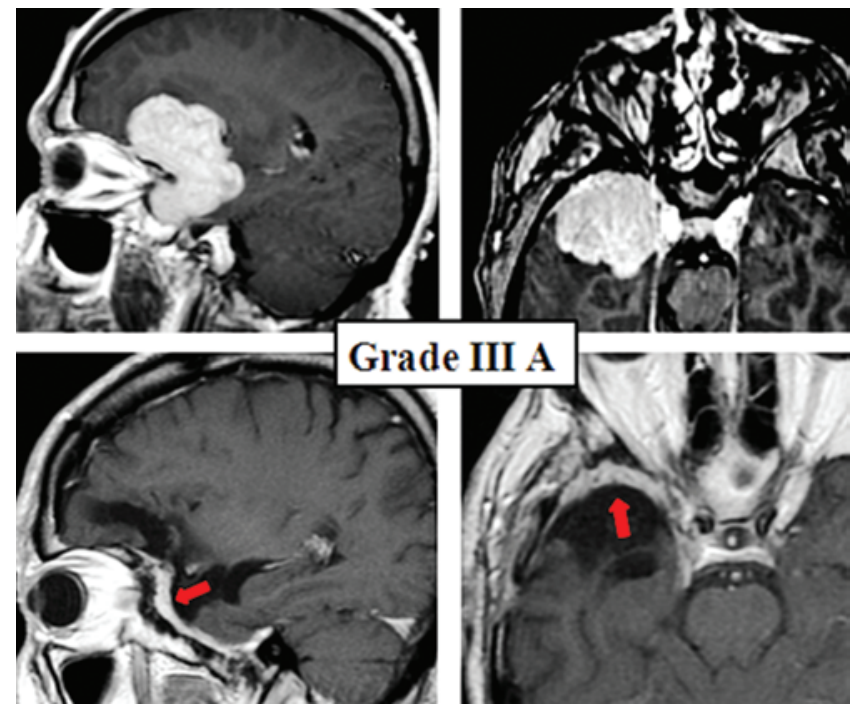

FIG. 7. Extent of resection is shown in T1-weighted MRI sequences obtained with contrast depicting modified Kobayashi Grade IIIA tumor removal. The red arrows indicate the residual enhancing dural tail. Figure is available in color online only.

gressive resection was primarily performed for sphenocavernous (67\% of which underwent complete resection) and tuberculum sellae CSM (83\%).

The association between extent of resection and recovery of preoperative CND was explored. Partial CN function recovery was seen in $53.3 \%$ of patients who underwent complete resection compared with $65.5 \%$ of patients who did not undergo complete resection ( $\mathrm{p}=0.4$, Pearson chi-square test); complete resection did not improve the chances of preoperative CND recovery in our study.

\section{Clinical Outcomes}

The patients' functional outcomes were determined using the KPS. The mean and median KPS scores at admission were $80.4 \pm 9.5$ and 80 , respectively (range 50-90), whereas the mean and median KPS scores at the last follow-up were $75.5 \pm 23.5$ and 80 , respectively (range $0-90$ ). The difference in KPS scores between patients who underwent surgery alone compared with those who had surgery plus adjuvant SRS was not statistically significant. KPS scores improved in 13 (20\%) patients, remained the same in $41(63 \%)$, and worsened in $11(17 \%)$ patients. Five deaths were noted in the group of patients who experienced wors-

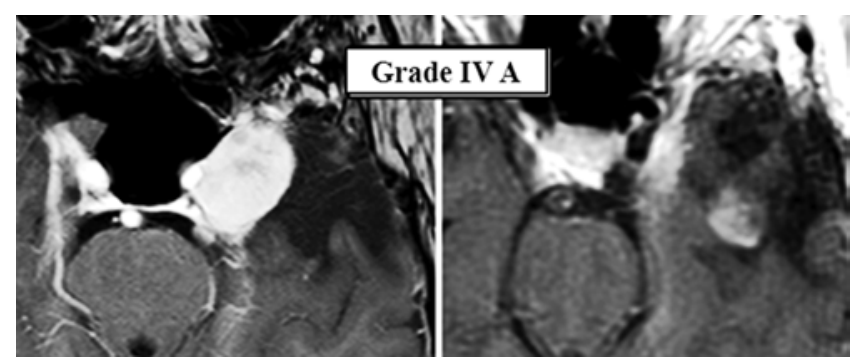

FIG. 8. Extent of resection is shown in T1-weighted MRI sequences obtained with contrast depicting modified Kobayashi Grade IVA tumor removal.

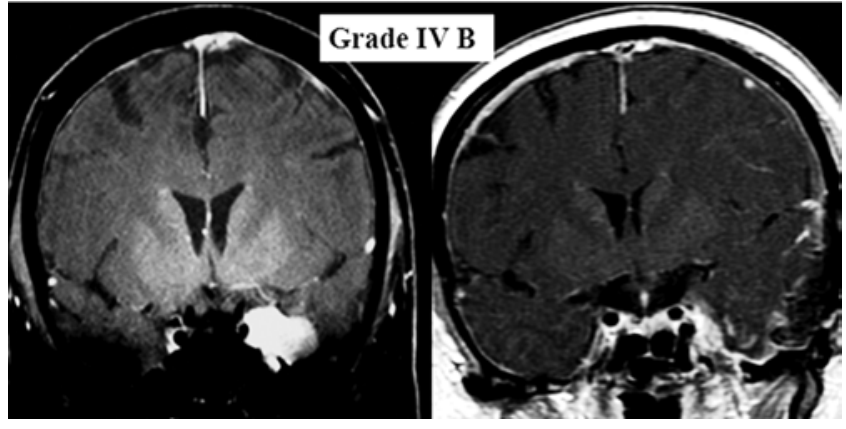

FIG. 9. Extent of resection is shown in T1-weighted MRI sequences obtained with contrast depicting modified Kobayashi Grade IVB tumor removal.

ening KPS scores, 3 of which were due to unrelated causes. Good recovery was defined as having the same or better KPS score at the last follow-up compared with the preoperative KPS score. Postoperative complications (new CND or others) did not influence KPS scores of patients at their last follow-up. Good outcomes at the last follow-up were similar in the cohort of patients without postoperative complications compared with those with postoperative complications ( $86.9 \%$ vs $79.8 \%$; $p=0.4)$. Stable or improved KPS scores were noted for patients who underwent surgery with adjuvant SRS compared with patients who underwent microsurgery alone $(95.8 \%$ vs $74.7 \%$, respectively; $p=0.05)$. However, binomial logistic regression failed to identify significant factors predicting good outcome (i.e., the same or better KPS score).

\section{Deaths}

There were no deaths within the first 30 days after surgery. Although in our series 5 deaths were reported at the last follow-up, 3 of these were not related to a neurosurgical etiology or procedure. One patient had a history of multiple intracranial resections for meningiomas at different locations. A few years after his surgery for treatment of CSM, the patient underwent a surgical intervention for a posterior fossa meningioma complicated by hydrocephalus and status epilepticus, which progressed to coma and death.

The second death involved a patient who presented with a sphenopetroclival meningioma. The patient underwent a 2-staged surgical procedure, which was followed by aggressive recurrence of the tumor (WHO Grade 1-2),

TABLE 8. Relationship between spatial tumor location and extent of resection*

\begin{tabular}{ccc}
\hline & \multicolumn{2}{c}{$\begin{array}{c}\text { Modified Kobayashi Tumor Removal Grading } \\
\text { System }\end{array}$} \\
\cline { 2 - 3 } Sekhar's Classification & Grades I-IIIA & Grades IIIB-V \\
\hline Grade I & 19 & 3 \\
\hline Grade II & 4 & 6 \\
\hline Grade III & 1 & 16 \\
\hline Grade IV & 2 & 10 \\
\hline Grade V & 1 & 3 \\
\hline
\end{tabular}

* Values are expressed as the number of patients. 
TABLE 9. Relationship between apparent origin of tumor and extent of resection

\begin{tabular}{lcc}
\hline & \multicolumn{2}{c}{ No. of Patients } \\
\cline { 2 - 3 } \multicolumn{1}{c}{ Origin } & $\begin{array}{c}\text { Grades I-IIIA } \\
\text { Resection }\end{array}$ & $\begin{array}{c}\text { Grades IIIB-V } \\
\text { Resection }\end{array}$ \\
\hline Primary CS & 1 & 10 \\
\hline Sphenoid wing CS & 18 & 9 \\
\hline Sphenopetrosal CS & 1 & 2 \\
\hline Sphenoclinoidal CS & 0 & 2 \\
\hline Sphenopetroclival CS & 0 & 6 \\
\hline Tuberculum sellae CS & 5 & 1 \\
\hline Clinoidal & 1 & 0 \\
\hline Petroclival & 1 & 8 \\
\hline
\end{tabular}

requiring resection and radiation therapy. Secondary to perioperative morbidities, which included hydrocephalus requiring ventriculoperitoneal shunt, septicemia, and renal failure, the patient succumbed to the aforementioned medical issues.

\section{Morbidities \\ New CNDs}

New postoperative CND was assessed at the first clinical follow-up after the surgery. Postoperative CND was noted in 35 (54\%) patients, among whom CN III deficit (24.6\%) was the most common (Table 7). At the last follow-up (mean 60.8 months, range 3-199 months), complete recovery was seen in $62.5 \%$ of patients. Two patients developed transient deterioration in their vision secondary to manipulation of $\mathrm{CN}$ II, which recovered completely at their first clinical follow-up. Permanent worsening of an existing right homonymous hemianopia was seen in 1 patient. Two patients developed postoperative swallowing dysfunction.

\section{Factors Affecting Development of New CNDs}

We first assessed the existence of any preoperative factors associated with a higher incidence of CNDs. Sekhar's classification grade was noted among the patients with and without new CNDs. ICA encasement by the tumor showed no significant correlation with development of new CNDs. Furthermore, no significant correlation was noted between the incidence of new CNDs among patients in the group that had complete resection compared with those with modified Kobayashi tumor removal Grades IVA, IVB, and V.

A comparison was made of the CND recovery status among the patients with CNDs prior to surgery and in those who developed CNDs after the surgery was done. Complete or partial recovery of $\mathrm{CNs}$ in patients with CNDs identified postoperatively compared with those with CNDs preoperatively was higher, although not significantly $(74.2 \%$ vs $64.6 \% ; \mathrm{p}=0.2)$.

\section{Other Morbidities}

One patient developed postoperative hemiparesis, which was probably due to vascular insult. Of the $5 \mathrm{pa}-$ tients with hemiparesis preoperatively, 1 had complete recovery, 1 had partial recovery, and 3 had no improvement.
A CSF leak developed in 3 patients, and 1 of the patients developed a pseudomeningocele. Postoperative meningitis and superficial wound infection were noted in 2 cases each. Seven patients developed hydrocephalus, and a ventriculoperitoneal shunt was required for 6 patients. Transient endocrine dysfunction was seen in 2 cases postoperatively. One patient was diagnosed with abnormal EEG activity, suggestive of seizures. Postoperative drug-related fever and deep vein thrombosis leading to pulmonary embolism were seen in $1(1.5 \%)$ patient each.

\section{Tumor Control and Recurrence}

The mean follow-up time in our patients was 60.8 months (range 3-199 months). To analyze tumor recurrence, we divided patients into 2 groups: 1) microsurgery $(\mathrm{n}=41)$, and 2) microsurgery plus adjuvant SRS $(\mathrm{n}=24)$. Eleven (26.8\%) recurrences were recorded in the microsurgery group, whereas $1(4.1 \%)$ recurrence was noted in the group that received postoperative SRS. The mean time to recurrence was 53 months. Kaplan-Meier analysis was used to determine progression-free survival (Fig. 10) and to calculate the hazard function (Fig. 11). Tumor recurrence was significantly lower in the cohort of patients to whom adjuvant SRS was administered $(p=0.009)$.

Patients exhibiting tumor recurrence were managed as follows. Four were treated by radiosurgery alone, radiotherapy (RT) was administered in 2 cases, 4 patients underwent repeat resection, and 2 underwent resection followed by adjuvant radiosurgery (Fig. 12). Meanwhile, 2 patients showed asymptomatic tumor progression, for which adjuvant SRS was administered; the 2 patients were stable at their last follow-up visits (36 months and 27 months after SRS, respectively) and were managed conservatively.

Multivariable Cox regression analysis was used to test the association between the use of adjuvant SRS and recurrence rate. Adjuvant SRS was significantly associated with improved tumor control after adjusting for patient

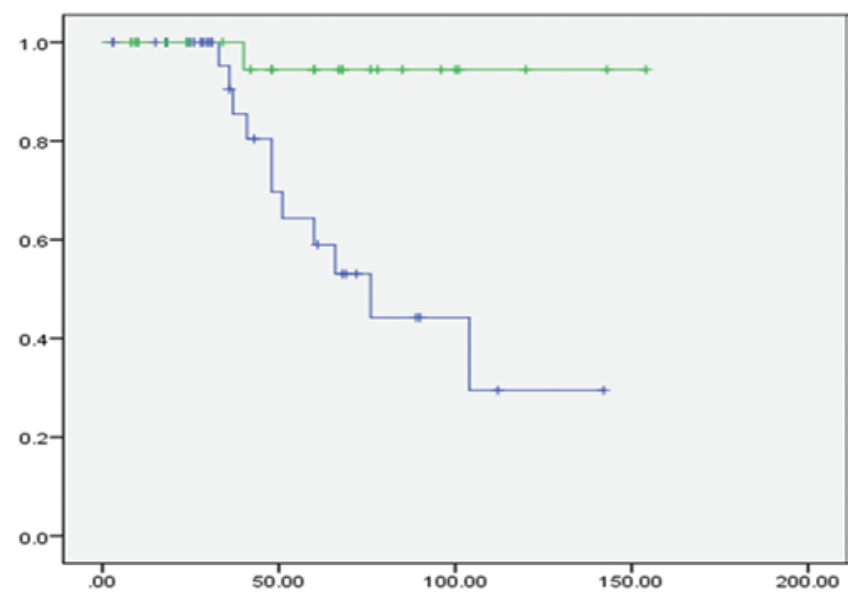

FIG. 10. A Kaplan-Meier survival function graph showing recurrences between the 2 cohorts. Patients managed by microsurgery alone are shown by the blue line. Patients managed by safe maximal microsurgery followed by adjuvant SRS for the surgical residual are shown by the green line. Note: The censored image is generated by the software to represent the drop in the number of subjects before the last follow-up. In the ideal statistical world, the vertical bars should be none to minimum. Figure is available in color online only. 


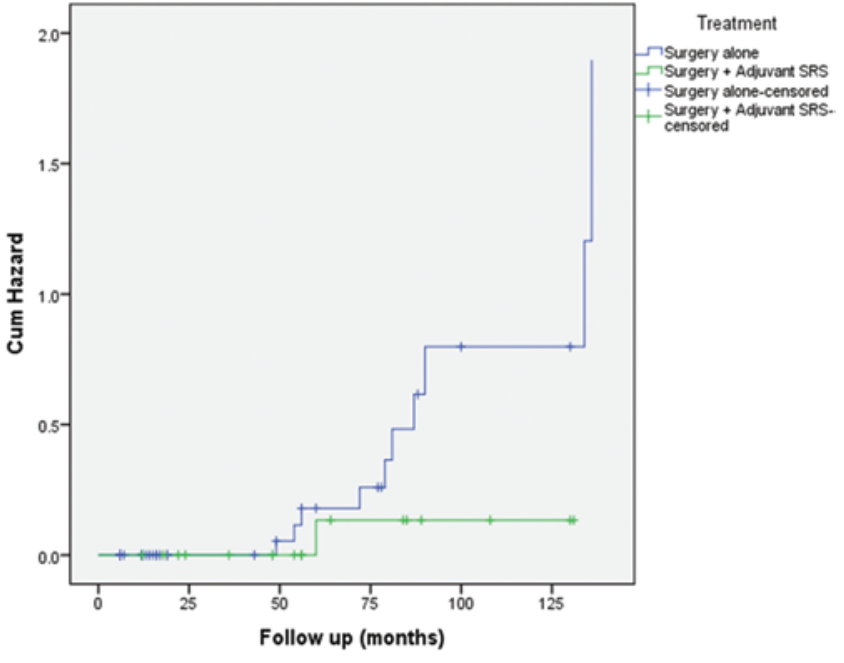

FIG. 11. A Kaplan-Meier hazard function graph showing the hazard of recurrence at long-term follow-up between the 2 cohorts. Patients managed by microsurgery alone are shown by the blue line. Patients managed by safe maximal microsurgery followed by adjuvant SRS for the surgical residual are shown by the green line. The hazard of recurrence was decreased by a factor of 27 in patients who received adjuvant Gamma Knife for microsurgical residual. Figure is available in color online only.

age, existence of CNDs, secondary cavernous involvement, ICA encasement, extent of resection, and WHO grade $(\mathrm{p}=0.009$; OR 0.036; 95\% CI 0.003-0.430) (Table 10). Analyzing the OR showed that the protective effect of surgery plus SRS was 27 times higher than surgery alone.

\section{Illustrative Case Showing a Delayed Recurrence}

A 62-year-old woman presented with recurrent CSM in December 2010. She complained of left-sided numbness and tingling sensation of the face and tongue, which was accompanied by episodes of sharp pain. These symptoms had gradually worsened over the prior year, starting in 2009. In 1995 the patient underwent surgery for a giant (7-cm) MF WHO Grade I meningioma, and gross-total resection was achieved (Fig. 13). In 2000, she underwent Gamma Knife radiosurgery for a small recurrent mass near the foramen ovale (Fig. 14). Subsequently she had radiological follow-up annually and underwent resection in 2011 for a recurrent mass (Fig. 15) (123 months after her last SRS), presenting with CN VI palsy and invasion of the CS extending into the infratemporal fossa through the foramen ovale. Postoperatively, the patient showed a nearcomplete recovery of her CN VI palsy.

The literature was reviewed to identify similar cases with delayed recurrence and to estimate the incidence and the time patterns of recurrence of CSM after radiosurgery, thereby elucidating the importance of long-term follow-up (Table 11). $1,6,9,10,21,30,32,41$

\section{Discussion}

The last 2 decades have again seen a significant paradigm shift in the management of meningiomas involving
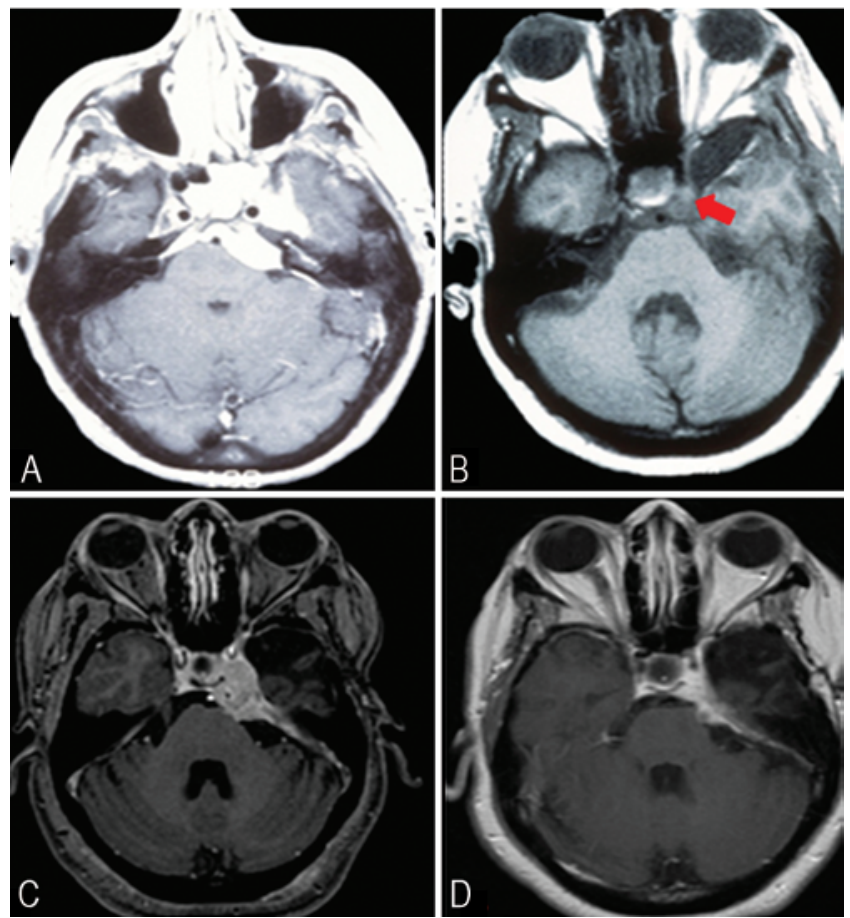

FIG. 12. Pre- and postoperative imaging ( $A$ and $B$ ) of a meningioma based in the CS and petroclival region. The red arrow points toward a small tumor residual postresection. A recurrent mass lesion that was treated by Gamma Knife (C) and subsequently underwent near-complete shrinkage at 96 months follow-up (D) is shown. Figure is available in color online only.

the CS, with convincing tumor control achieved by SRS (Table 1). Recent microsurgical series on CSM advocate safe maximal decompression followed by adjuvant SRS as opposed to complete resection goals, such as those published in the late 20th century. 1,5,25,27,31,41 Notably, the mean recurrence rate in the primary SRS group was $7.5 \%$, versus $15.6 \%$ in the surgery with or without SRS/RT (Tables 1 and 2). Although this may be a significant difference, there are variables (especially the mean size of the tumor among the different groups) which may have contributed. Furthermore, recent surgical series, where adjuvant SRS/RT is part of the treatment strategy, have demonstrated that recurrence rates are comparable to those of SRS series.

TABLE 10. Multivariate logistic regression analysis model to determine the independent factors predicting tumor recurrence

\begin{tabular}{lcrrr}
\hline & & & \multicolumn{2}{c}{$95 \% \mathrm{Cl}$} \\
\cline { 4 - 5 } \multicolumn{1}{c}{ Covariates } & p Value & \multicolumn{1}{c}{ OR } & Lower & Upper \\
\hline Age <65 yrs & 0.508 & 0.562 & 0.003 & 0.430 \\
\hline Preop CND & 0.968 & $374,281.347$ & 0.000 & 3.636 \\
\hline Secondary origin CS & 0.216 & 0.306 & 0.047 & 1.994 \\
\hline ICA encasement & 0.386 & 0.463 & 0.081 & 2.647 \\
\hline Complete resection & 0.093 & 0.225 & 0.039 & 1.283 \\
\hline WHO grade & 0.099 & 0.224 & 0.038 & 1.328 \\
\hline $\begin{array}{l}\text { Surgery + Gamma Knife for } \\
\quad \text { residual }\end{array}$ & $0.009^{*}$ & 0.036 & 0.003 & 0.430 \\
\hline
\end{tabular}

* $p$ value is significant $(<0.05)$. 


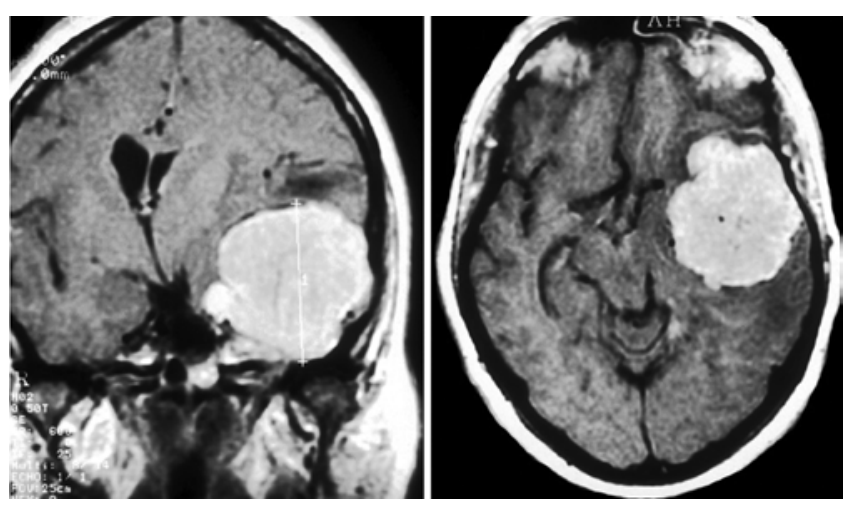

FIG. 13. A preoperative T1-weighted MR image from 1995 shows a giant MF meningioma depicted in a coronal view (left) and axial view (right).

\section{Resectability of Meningiomas Involving the CS}

Various factors highlighted in the literature have been shown to influence the resectability of CSM. Five of these factors are as follows.

1) The extent of ICA involvement and encasement by the meningioma reflected by Hirsch grading, modified Hirsch grading, and Sekhar's classification., 1,22,23,30,32,39,41 Tumors invading the walls of intracavernous ICA have frequently limited the potential for gross-total resection. In our experience, any degree of ICA encasement significantly influenced a tumor's resectability.

2) Meningiomas invading the CS often lose the natural arachnoid and medial intradural plane of dissection.

3) Tumor consistency plays an important role when dissecting the tumor from the neurovascular structures in the parasellar compartment. ${ }^{9}$ Tumors that have a more fibrotic component or exhibit invasive histopathological features are difficult to dissect from the CNs and ICA, often necessitating intentional subtotal removal of the tumor to allow for maximal functional preservation of the CNs. ${ }^{38}$

4) Reoperations for treatment of CSM following previous resection or SRS may account for difficulty in resection due to loss of anatomical planes ${ }^{30}$ or a possible change in tumor consistency following SRS. However, prior reports noted no statistically significant relationship between prior surgery or prior RT. ${ }^{9}$ In our experience, 6 patients underwent repeat surgery for treatment of CSM following recurrence. For $4(67 \%)$ of these patients, $\leq$ Grade IVA resection
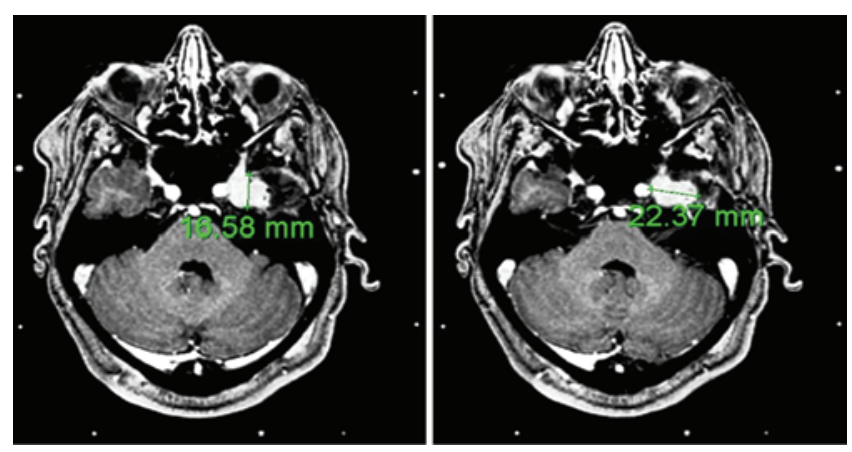

FIG. 14. A pre-Gamma Knife T1-weighted MR image from 2000 shows a recurrent tumor after macroscopic gross-total resection. Left and right panels represent the postframe/pretreatment Gamma Knife axial view of the CSM. Figure is available in color online only.
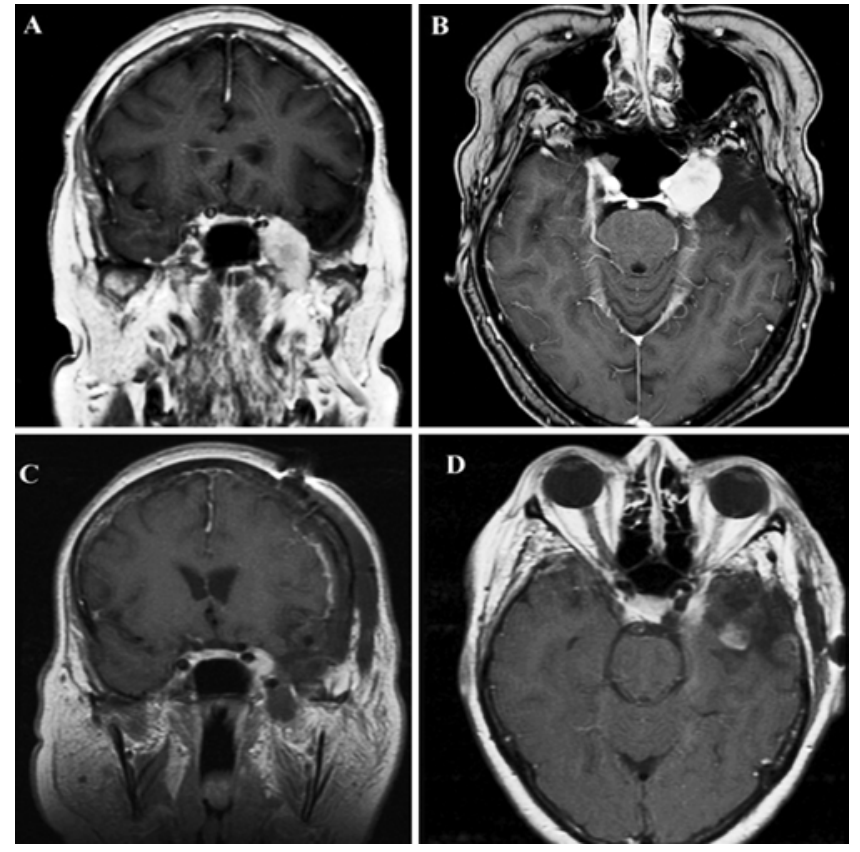

FIG. 15. A and B: A preoperative T1-weighted MR image from 2011 shows involvement of the CS and breach of the MF floor with infratemporal extension of the recurrent tumor. C and D: A postoperative MR image from 2011 confirms Grade IVA resection of the recurrent meningioma.

was achieved, whereas complete microscopic removal was achieved in only 2 (33\%) of these patients.

5) The degree of extracavernous extension involving the orbital apex, superior orbital fissure, and petroclival dura limits complete resectability.

Based on our series, the "stopping rule" and extent of resection for CSM rely on the notion of safe maximal resection. The latter is mainly dictated by the consistency of the tumor invading the CS. In cases where the tumor was soft and easily debulked using microdissection and suction, there was a higher likelihood for a complete or near-complete resection. Because we found that the $\mathrm{CN}$ recovery rates and final clinical outcome were not dependent on the extent of resection, our practices for pursuit of complete resection have significantly decreased to include only tumors of softer consistency, which can be removed with minimal manipulation of the parasellar structures. In cases of young patients with minimal comorbidities who have higher-grade meningiomas, we consider more aggressive resection followed by SRS early in the postoperative period (i.e., within 3-6 months of surgery).

\section{Clinical Outcomes at Long-Term Follow-Up}

A review of the English-language literature was conducted for articles on patients with CSM who underwent microsurgery with or without SRS/RT from 1990 onward (Table 11).

The articles reporting at least 24 months of follow-up were included. The frequency of preoperative CNDs was examined, and it was found that CN II and CN III were most frequently involved. Partial recovery was noted in $14 \%-67 \%$ of the CNs involved. CNs most amenable to re- 
TABLE 11. Clinical outcomes of preoperative CND at last follow-up among contemporary microsurgical series

\begin{tabular}{|c|c|c|c|c|c|c|}
\hline Authors \& Year & Mean Follow-Up & $\begin{array}{l}\text { Most Commonly } \\
\text { Involved CN }\end{array}$ & $\begin{array}{c}\% \text { of CNs Showing } \\
\text { Partial or Complete } \\
\text { Recovery }\end{array}$ & $\begin{array}{c}\text { CNs Showing } \\
\text { Maximum Recovery } \\
\text { (complete or partial) }\end{array}$ & $\begin{array}{l}\text { CNs Showing } \\
\text { Worst Recovery }\end{array}$ & $\begin{array}{l}\% \text { of Patients } \\
\text { Undergoing Complete } \\
\text { Microscopic Resection }\end{array}$ \\
\hline Pichierri et al., 2009 & 9.7 yrs & III & NA & V & III, IV & 15 \\
\hline Sindou et al., 2007* & $8.3 \mathrm{yrs}$ & II, III & 41 & ॥ & $\mathrm{VI}$ & 12 \\
\hline Abdel-Aziz et al., 2004 & $96 \mathrm{mos}$ & III & 67 & III & IV & 63 \\
\hline De Jesús et al., 1996 & $33.8 \mathrm{mos}$ & NA & NA & NA & NA & 61 \\
\hline Knosp et al., 1996 & $3-84$ mos & III & 33 & III & IV & 17 \\
\hline Cusimano et al., 1995 & $29 \mathrm{mos}$ & NA & NA & NA & NA & 80 \\
\hline De Monte et al., 1994 & $45 \mathrm{mos}$ & II & 14 & VI & IV, V, VII, VIII & 76 \\
\hline
\end{tabular}

* No clear segregation of preoperative and new CND.

$\dagger$ These investigators calculated new deficits by considering the denominator as total number of CNs at risk (e.g., 17 optic nerves, 78 extraocular nerves, and 97 trigeminal nerves).

covery were CN V and CN III, whereas CN IV showed the least degree of recovery (Table 11). In our study, partial recovery was noted in $61.3 \%$ of patients; however, only $23 \%$ achieved complete recovery. There was no significant positive correlation between the extent of tumor removal and improvement in $\mathrm{CN}$ function. In consideration of the above findings, we do not advocate for aggressive resection.

Our study did not find any independent factor predictive of good functional recovery (i.e., improved KPS score) in our patients. However, improvement in preoperative CND represented a trend in predicting good clinical outcomes (i.e., the same or better KPS score).

\section{Tumor Control and Temporal Patterns of Recurrence Among Patients With CSM}

The tumor control for the major CSM series, in which patients were treated with surgery with or without SRS/RT (as reported by Sindou et al.), ranged from $81 \%$ to $94.1 \%$ over a period of $2-8.3$ years. ${ }^{41}$ Since then, only 1 microsurgical CSM series has been published, with a tumor control rate of $75.5 \%$ and the longest mean follow-up (9.7 years). ${ }^{32}$ For tumors located primarily in the CS with no MF or posterior extension, tumor control is significantly better with SRS alone compared with patients treated by complete or subtotal resection alone. ${ }^{44}$ However, for meningiomas involving the CS that have a significant extracavernous component with mass effect, resection with or without SRS/ RT is necessary. ${ }^{1,5,6,21,27,30,41}$ Currently there are no randomized controlled trials or even a nonrandomized prospective controlled study published that compare the 2 treatment modalities as the primary treatment. Maruyama et al. ${ }^{27}$ published a prospective noncontrolled study where tumors located in the CS and away from the optic apparatus were treated with radiosurgery alone; whereas tumors that were $>3 \mathrm{~cm}$ in diameter, or that compressed the optic apparatus or brainstem or extended into multiple cranial fossae, were treated with nonradical resection followed by adjuvant SRS. With such appropriate patient selection, they were able to achieve an actuarial tumor control rate of $94 \%$ at 5 years.
Various factors have been noted to influence recurrence and progression. Over the last 3 decades, as data have accumulated for long-term follow-up of patients treated with conservative approaches with or without adjuvant SRS, the paradigm of the extent of resection needed to achieve optimal tumor control has shifted from aggressive maximal resection to safe maximal resection. .,6, $, 11,27,31,32,37,41,48 \mathrm{Re}$ cent studies with long-term follow-up suggest no definite correlation of aggressive resection with better long-term tumor control. ${ }^{1,32,41}$ We did not find any correlation of complete resection with better long-term tumor control in our cohort. Moreover, in our study, we found that safe maximal resection followed by adjuvant SRS can independently decrease the odds of recurrence and achieve excellent tumor control. The recurrence rate in our study was $18.4 \%$, whereas the range in the literature varies from $8.7 \%$ to $24.5 \%$ (Table 2). After changing our strategy to provide adjuvant SRS after conservative decompression, we had only 1 recurrence (4\%). Our results, in conjunction with the previous studies, strongly endorse a conservative approach in tumors occupying the parasellar compartment. After appropriate patient selection, adjuvant SRS/RT is often necessary, which seems to provide higher tumor control rates.

The histological behavior of the tumor has also been suggested to influence its growth. ${ }^{1,2,29,38}$ Anaplastic tumors have higher recurrence rates; ${ }^{1,30,32}$ therefore, we elect to administer SRS/RT as an adjuvant after surgery in such cases. Some studies have suggested that a high proliferative index among CSM increases the chances of recurrence or progression, although no statistical association has been made yet. ${ }^{1}$ At our center, the documentation of Ki 67 started toward the latter half of our study time frame; there was not enough data available to report in the present study. However, future studies are planned that will incorporate not only proliferative index, but also other histopathological features including mitotic figures, nuclear polymorphism, and so on.

Last, it has also been suggested that anatomical patterns of invasion have an influence on recurrence. The extension of tumor into the orbit or superior orbital fissure has 
been associated with increased recurrence in some studies. ${ }^{4,24,32,38}$ In our series, 7 CSMs had superior orbital fissure extension, of which $3(43 \%)$ recurred.

Because one of our patients had a recurrence after 123 months of SRS (used to treat recurrence after microsurgery), we assessed temporal patterns of recurrence in CSM managed surgically. The literature from January 1990 to May 2011 was reviewed for studies involving CSM treated with microsurgery with or without SRS/RT (Table 2). Studies with $<24$ months of follow-up and/or lesions $<$ $20 \mathrm{~mm}^{3}$ were excluded. Similarly, the literature was also reviewed for studies involving CSM treated by SRS primarily or for microsurgical recurrence (Table 1). The majority of tumors recurred within the first 5 years. Previous studies showed that the chances of recurrence are highest within 60 months of microsurgery or SRS (Table 2). Sindou et al. concluded that time to the tumor recurrence in their series ranged from 2 to 9 years, after which time the tumor showed no tendency to recur. ${ }^{41}$ Given that recurrence can occur even after 10 years, long-term follow-up beyond 10 years should be considered.

\section{Is an Algorithm for Treatment of CSM Possible?}

In our view, CSMs are heterogeneous skull base lesions for which a rigid treatment algorithm may not be possible. We have summarized the treatment strategies for meningiomas invading the parasellar compartment in Table 6. Among benign CSMs, aggressive resection (Grades IIIIB) may be reserved for sphenocavernous lesions not encasing the intracavernous ICA, petrosal-cavernous or petroclival-cavernous lesions with a posterior CS tumor component, and tuberculum sellae CSM not encasing the intracavernous ICA (Tables 6 and 9).

It is noteworthy that, in our study, the extent of resection did not statistically improve the likelihood of complete recovery of $\mathrm{CN}$ function. Previous studies suggest that aggressive resection is helpful in patients with complete ophthalmoplegia; however, no statistical correlation has been made. ${ }^{32}$ There may be a few cases in which complete recovery may be possible; however, the patient should be well informed about the chances of $\mathrm{CN}$ recovery after the surgical removal. A reasonable question to consider is how useful the incomplete recovery of CNs II, III, IV, and VI is for the patient's quality of life. Limitations in our study design did not allow us to objectively measure this; however, this may certainly be a crucial primary end point for future prospective studies. Although the extent of resection did not improve rates of positive $\mathrm{CN}$ outcomes, we believe that relieving the mass effect of the tumors added a definite advantage in improving $\mathrm{CN}$ outcomes. Whether outcomes were significantly different than if SRS had been used alone, or if improvement of $\mathrm{CN}$ function through surgery confers additional advantages in terms of quality of life, needs to be determined.

For treating recurrences, the primary factors that should be considered are previous histology reports and anatomical location of the tumor. If previous histology type included atypical grade or worse, aggressive microsurgery is attempted. In cases where the recurrent CSM shows "in-site" recurrence, SRS is the preferred modality. An exception is when the patient develops severe cranial neuropathy. In this case, safe maximal surgical decompression followed by adjuvant SRS for residual tumor is desirable. Similarly, if the recurrence extends beyond the original tumor site, safe maximal resection followed by adjuvant SRS is done at our center.

\section{Limitations of the Study}

Because this is a retrospective study, bias inherent to the study design was unavoidable. The mean follow-up of patients in our study was 60.8 months; however, even longer follow-up (a mean $>10$ years) would be necessary to convincingly report the relative efficacy of tumor control among different treatment modalities. Also, our results and conclusions are based on a single surgeon's experience with 65 patients and may not be representative of a larger patient population. Finally, this study only included CSM treated primarily by resection initially and not by SRS/ RT; therefore, comparison of symptomatic CSM treated primarily with SRS was beyond the scope of this study.

Objective data from debulking alone may show advantages of reducing the dose administered to patients while doing SRS compared with those who primarily underwent SRS for a similar-size tumor. This concept was beyond the scope of our study. However, it may be an important question to ask for addition to the neurosurgical literature.

\section{Conclusions}

In the management of symptomatic CSM, the challenge includes achieving a balance among optimal resection, restoration of $\mathrm{CN}$ functions, and good quality of life. In our study, complete recovery of preoperative CND was possible in $23 \%$ of patients with CSM after microsurgery. However, these rates may be different than the cohort of patients treated with radiosurgery alone, and these comparison rates are not addressed in our study. ${ }^{28,43}$ Modified Kobayashi Grades I-IIIB were achieved in $41.5 \%$ of cases. Aggressive resection neither improved tumor control nor did it increase the likelihood of improving preoperative CND. Maximal intracavernous decompression followed by adjuvant SRS shortly after surgery can significantly decrease the recurrence rate in patients with CSM, to as low as $4.1 \%$ compared with maximal intracavernous resection alone. The efficacy of maximal intracavernous resection with SRS versus SRS alone is not examined in the present study.

\section{Acknowledgments}

We would like to thank Jennifer Pryll for her assistance in making the illustrations for Figures 1 to 5 in our manuscript.

\section{References}

1. Abdel-Aziz KM, Froelich SC, Dagnew E, Jean W, Breneman JC, Zuccarello M, et al: Large sphenoid wing meningiomas involving the cavernous sinus: conservative surgical strategies for better functional outcomes. Neurosurgery 54:13751384, 2004

2. Amatya VJ, Takeshima Y, Sugiyama K, Kurisu K, Nishisaka T, Fukuhara T, et al: Immunohistochemical study of Ki-67 (MIB-1), p53 protein, p21WAF1, and p27KIP1 expression in benign, atypical, and anaplastic meningiomas. Hum Pathol 32:970-975, 2001 
3. Chanda A, Nanda A: Anatomical study of the orbitozygomatic transsellar-transcavernous-transclinoidal approach to the basilar artery bifurcation. J Neurosurg 97:151-160, 2002

4. Cophignon J, Lucena J, Clay C, Marchac D: Limits to radical treatment of spheno-orbital meningiomas. Acta Neurochir Suppl (Wien) 28:375-380, 1979

5. Couldwell WT, Kan P, Liu JK, Apfelbaum RI: Decompression of cavernous sinus meningioma for preservation and improvement of cranial nerve function. Technical note. J Neurosurg 105:148-152, 2006

6. Cusimano MD, Sekhar LN, Sen CN, Pomonis S, Wright DC, Biglan AW, et al: The results of surgery for benign tumors of the cavernous sinus. Neurosurgery 37:1-10, 1995

7. D'Ambrosio AL, Mocco J, Hankinson TC, Bruce JN, van Loveren HR: Quantification of the frontotemporal orbitozygomatic approach using a three-dimensional visualization and modeling application. Neurosurgery 62 (3 Suppl 1):251-261, 2008

8. Day JD: Cranial base surgical techniques for large sphenocavernous meningiomas: technical note. Neurosurgery 46:754-760, 2000

9. De Jesús O, Sekhar LN, Parikh HK, Wright DC, Wagner DP: Long-term follow-up of patients with meningiomas involving the cavernous sinus: recurrence, progression, and quality of life. Neurosurgery 39:915-920, 1996

10. DeMonte F, Smith HK, Al-Mefty O: Outcome of aggressive removal of cavernous sinus meningiomas. J Neurosurg 81:245-251, 1994

11. Dolenc V, Kregar T, Ferluga M, Fettich M, Morina A: Treatment of tumors invading the cavernous sinus, in Dolenc VV (ed): The Cavernous Sinus: A Multidisciplinary Approach to Tumors and Vascular Lesions. Vienna: Springer, 1987, pp 377-391

12. dos Santos MA, de Salcedo JBP, Gutiérrez Diaz JA, Calvo FA, Samblás J, Marsiglia H, et al: Long-term outcomes of stereotactic radiosurgery for treatment of cavernous sinus meningiomas. Int J Radiat Oncol Biol Phys 81:1436-1441, 2011

13. Dufour H, Muracciole X, Métellus P, Régis J, Chinot O, Grisoli F: Long-term tumor control and functional outcome in patients with cavernous sinus meningiomas treated by radiotherapy with or without previous surgery: is there an alternative to aggressive tumor removal? Neurosurgery 48:285-296, 2001

14. Eliot TS: Four Quartets. New York: Harcourt, Brace, 1943

15. Goldsmith BJ, Wara WM, Wilson CB, Larson DA: Postoperative irradiation for subtotally resected meningiomas. A retrospective analysis of 140 patients treated from 1967 to 1990. J Neurosurg 80:195-201, 1994

16. Hakuba A, Tanaka K, Suzuki T, Nishimura S: A combined orbitozygomatic infratemporal epidural and subdural approach for lesions involving the entire cavernous sinus. J Neurosurg 71:699-704, 1989

17. Hasegawa T, Kida Y, Yoshimoto M, Koike J, Iizuka H, Ishii D: Long-term outcomes of Gamma Knife surgery for cavernous sinus meningioma. J Neurosurg 107:745-751, 2007

18. Kawase T, Toya S, Shiobara R, Kimura C, Nakajima H: Skull base approaches for meningiomas invading the cavernous sinus, in Dolenc VV (ed): The Cavernous Sinus: A Multidisciplinary Approach to Tumorous and Vascular Lesions. Vienna: Springer, 1987, pp 346-354

19. Kimball MM, Friedman WA, Foote KD, Bova FJ, Chi YY: Linear accelerator radiosurgery for cavernous sinus meningiomas. Stereotact Funct Neurosurg 87:120-127, 2009

20. Klink DF, Sampath P, Miller NR, Brem H, Long DM: Longterm visual outcome after nonradical microsurgery patients with parasellar and cavernous sinus meningiomas. Neurosurgery 47:24-32, 2000

21. Knosp E, Perneczky A, Koos WT, Fries G, Matula C: Menin- giomas of the space of the cavernous sinus. Neurosurgery 38:434-444, 1996

22. Kotapka MJ, Kalia KK, Martinez AJ, Sekhar LN: Infiltration of the carotid artery by cavernous sinus meningioma. J Neurosurg 81:252-255, 1994

23. Landeiro JA, Ribeiro CH, Lapenta MA, Flores MS, Lopes $\mathrm{CA}$, Marins J: [Meningiomas of the cavernous sinus: the surgical resectability and complications.] Arq Neuropsiquiatr 59:746-753, 2001 (Portuguese)

24. Larson JJ, van Loveren HR, Balko MG, Tew JM Jr: Evidence of meningioma infiltration into cranial nerves: clinical implications for cavernous sinus meningiomas. J Neurosurg 83:596-599, 1995

25. Lee JYK, Niranjan A, McInerney J, Kondziolka D, Flickinger JC, Lunsford LD: Stereotactic radiosurgery providing long-term tumor control of cavernous sinus meningiomas. J Neurosurg 97:65-72, 2002

26. Lemole GM Jr, Henn JS, Zabramski JM, Spetzler RF: Modifications to the orbitozygomatic approach. Technical note. J Neurosurg 99:924-930, 2003

27. Maruyama K, Shin M, Kurita H, Kawahara N, Morita A, Kirino T: Proposed treatment strategy for cavernous sinus meningiomas: a prospective study. Neurosurgery 55:10681075, 2004

28. Metellus P, Regis J, Muracciole X, Fuentes S, Dufour H, Nanni I, et al: Evaluation of fractionated radiotherapy and gamma knife radiosurgery in cavernous sinus meningiomas: treatment strategy. Neurosurgery 57:873-886, 2005

29. Ohkoudo M, Sawa H, Hara M, Saruta K, Aiso T, Ohki R, et al: Expression of p53, MDM2 protein and Ki-67 antigen in recurrent meningiomas. J Neurooncol 38:41-49, 1998

30. O'Sullivan MG, van Loveren HR, Tew JM Jr: The surgical resectability of meningiomas of the cavernous sinus. Neurosurgery 40:238-247, 1997

31. Pamir MN, Kiliç T, Bayrakli F, Peker S: Changing treatment strategy of cavernous sinus meningiomas: experience of a single institution. Surg Neurol 64 (Suppl 2):S58-S66, 2005

32. Pichierri A, Santoro A, Raco A, Paolini S, Cantore G, Delfini $\mathrm{R}$ : Cavernous sinus meningiomas: retrospective analysis and proposal of a treatment algorithm. Neurosurgery 64:10901101, 2009

33. Pollock BE, Stafford SL: Results of stereotactic radiosurgery for patients with imaging defined cavernous sinus meningiomas. Int J Radiat Oncol Biol Phys 62:1427-1431, 2005

34. Roche PH, Régis J, Dufour H, Fournier HD, Delsanti C, Pellet $\mathrm{W}$, et al: Gamma knife radiosurgery in the management of cavernous sinus meningiomas. J Neurosurg 93 (Suppl 3):68-73, 2000

35. Seçkin H, Avci E, Uluç K, Niemann D, Başkaya MK: The work horse of skull base surgery: orbitozygomatic approach. Technique, modifications, and applications. Neurosurg Focus 25(6):E4, 2008

36. Sekhar LN, Altschuler EM: Meningiomas of cavernous sinus, in Al-Mefty O (ed): Meningiomas. New York: Raven Press, 1991, pp 445-460

37. Sekhar LN, Sen CN, Jho HD, Janecka IP: Surgical treatment of intracavernous neoplasms: a four-year experience. Neurosurgery 24:18-30, 1989

38. Sen C, Hague K: Meningiomas involving the cavernous sinus: histological factors affecting the degree of resection. $\mathbf{J}$ Neurosurg 87:535-543, 1997

39. Shaffrey ME, Dolenc VV, Lanzino G, Wolcott WP, Shaffrey CI: Invasion of the internal carotid artery by cavernous sinus meningiomas. Surg Neurol 52:167-171, 1999

40. Shin M, Kurita H, Sasaki T, Kawamoto S, Tago M, Kawahara $\mathrm{N}$, et al: Analysis of treatment outcome after stereotactic radiosurgery for cavernous sinus meningiomas. J Neurosurg 95:435-439, 2001

41. Sindou M, Wydh E, Jouanneau E, Nebbal M, Lieutaud T: 
Long-term follow-up of meningiomas of the cavernous sinus after surgical treatment alone. J Neurosurg 107:937-944, 2007

42. Skeie BS, Enger PO, Skeie GO, Thorsen F, Pedersen PH: Gamma knife surgery of meningiomas involving the cavernous sinus: long-term follow-up of 100 patients. Neurosurgery 66:661-669, 2010

43. Spiegelmann R, Cohen ZR, Nissim O, Alezra D, Pfeffer R: Cavernous sinus meningiomas: a large LINAC radiosurgery series. J Neurooncol 98:195-202, 2010

44. Sughrue ME, Rutkowski MJ, Aranda D, Barani IJ, McDermott MW, Parsa AT: Factors affecting outcome following treatment of patients with cavernous sinus meningiomas. J Neurosurg 113:1087-1092, 2010

45. Tanriover N, Ulm AJ, Rhoton AL Jr, Kawashima M, Yoshioka N, Lewis SB: One-piece versus two-piece orbitozygomatic craniotomy: quantitative and qualitative considerations. Neurosurgery 58 (4 Suppl 2):ONS-229-ONS-237, 2006

46. Tew JJ, van Loveren H, Keller J: Atlas of Operative Microneurosurgery: Brain Tumors. Philadelphia: Saunders, 2001

47. Williams BJ, Yen CP, Starke RM, Basina B, Nguyen J, Rainey J, et al: Gamma Knife surgery for parasellar meningiomas: long-term results including complications, predictive factors, and progression-free survival. J Neurosurg 114:1571-1577, 2011

48. Wilson CB: Meningiomas: genetics, malignancy, and the role of radiation in induction and treatment. The Richard C. Schneider Lecture. J Neurosurg 81:666-675, 1994
49. Yamaki T, Tanabe S, Sohma T, Uede T, Shinya T, Hashi K: Feeding arteries of parasellar meningiomas-angiographic study of medial sphenoid ridge and tuberculum sellae meningiomas. Neurol Med Chir (Tokyo) 28:553-558, 1988

50. Zabramski JM, Kiriş T, Sankhla SK, Cabiol J, Spetzler RF: Orbitozygomatic craniotomy. Technical note. J Neurosurg 89:336-341, 1998

\section{Disclosures}

The authors report no conflict of interest concerning the materials or methods used in this study or the findings specified in this paper.

\section{Author Contributions}

Conception and design: Nanda. Acquisition of data: Thakur. Analysis and interpretation of data: Thakur, Sonig. Drafting the article: Nanda, Thakur. Critically revising the article: Sonig, Missios. Reviewed submitted version of manuscript: Nanda. Approved the final version of the manuscript on behalf of all authors: Nanda. Statistical analysis: Thakur, Missios.

\section{Correspondence}

Anil Nanda, Department of Neurosurgery, Louisiana State University Health Sciences Center-Shreveport, 1501 Kings Highway, Shreveport, LA 71103. email: ananda@1suhsc.edu. 